\title{
Helicopter Pilots and Low Back Pain: How to Manage the Risk
}

\section{Factors?}

\section{Gilvan V da Silva*}

Operational Human Performance Graduate Program, The Brazilian Air Force University, Brazil

Department of Environmental Medicine, Program of Ergonomics and Biomechanics, New York University, New York

\section{Research Article}

Volume 2 Issue 1

Received Date: December 16, 2017

Published Date: January 05, 2018

DOI: $10.23880 /$ eoij-16000130

*Corresponding author: Gilvan V. da Silva, Operational Human Performance Graduate Program, The Brazilian Air Force University, Av. Mal. Fontenelle, 1000, Rio de Janeiro-RJ 21740-002, Brazil, Email: gvs219@nyu.edu

\section{Abstract}

A high prevalence of LBP in helicopter pilots has been reported by several epidemiological surveys since the early 1960's. As pointed out by several authors the most important etiologic factor of LBP in helicopter pilots is the asymmetrical posture adopt during flight. The aim of the study is understand the pathomechanical model of the low back pain (LBP) that affects helicopter pilots in order to propose a risk management addressed to reduce this issue. A comprehensive literature review was performed to identify evidences about low back pain in helicopter pilots, risk factors related and some interventions/risk management adopted. In addition, a self-reported questionnaire was applied for LBP prevalence and pain characterization. Results showed asymmetrical in-flight posture; cockpit design/geometry; seat design; WBV; static posture; prolonged sitting; and flight duration as mainly risk factors and a higher prevalence of LBP among helicopter pilots as well as a significant influence of flight activity on pain features when compared to office workers. In order to solve the problem it will be necessary to provide a comprehensive solution composed by three different and complementary steps: a specific exercise program (as an immediate solution), the use of lumbar support (as a short term solution), and a proposal for redesign cockpit and seat (as a long term solution).

Keywords: Low Back Pain; Helicopter Pilot; Asymmetric Posture

\section{Introduction}

A high prevalence of low back pain (LBP) in helicopter pilots has been reported by several epidemiological surveys since the early 1960's [1-3]. Low back pain (LBP) among helicopter pilots is a well-recognized problem, with prevalence ranging from 44 to over $92 \%$. Therefore, it is generally felt that the helicopter pilots have an increase prevalence of LBP in comparison to the population as a whole (12-33\%) [4-6]. Helicopter and fighter pilots are the most affected by spine problems and discomfort among all pilots classes [1,7]. Evidence 


\section{Ergonomics International Journal}

confirmed by the findings of the helicopter pilots presenting the risk of develops LBP twice as the Fighter and Instructor pilots' risk [8].

The prevalence of LBP among members of military helicopter aircrew has been found to be high: $92 \%$ Australian pilots [9], 82\% British Royal Navy 1996 survey [10], 80\% British Royal Navy 2002 survey [11], 72\% Israelis AH-1S Cobra Helicopter aircrew [4], and 50.5\% Royal Norwegian Air Force Sea King aircrew [2]. In a survey of the British Army, Royal Air Force and Royal Navy, the incidence of LBP was higher among rotary-wing aircrews compared to fixed-wing aviators [12].

A survey performed in 2010 with RAF and civilian helicopter pilots, showed that this scenario has not changed, as the prevalence found was $83 \%$ among the RAF pilots and $82 \%$ among the civilians [3]. In a survey carried out in the Brazilian Air Force among helicopter pilots (military and civil), the prevalence of LBP was $44.6 \%$. Among these pilots, $98.2 \%$ reported pain during or immediately after flight [13]. Epidemiologic studies have been divided the helicopter pilots' population with LBP in two different groups: a small one $(11 \%)$ with chronic LBP (similar to idiopathic LBP in the general population) and a larger one (73\%) suffering the transient LBP [14]. The transient pain has been generally described as a typically dull pain without radiation, during few hours and normally disappearing after a briefly rest and/or when finished the flight activity $[15,16]$.

As pointed out by several authors the most important etiologic factor of LBP in helicopter pilots is the asymmetrical posture adopt during flight $[1,4,9,15,17-22]$. However there are some studies that have not found associations between asymmetric posture and LBP in helicopter pilots [23-25]. Due to the flight controls disposition the normal posture adopted by the helicopter pilots during flight is bend forward, twisted and bend to the left. In order to gain greater control of the cyclic stick, the pilots rest their forearm on their thigh, and consequently must flex the trunk forward [1]. Although forward flexion of the trunk is a necessary and common component of many complex everyday postures, it has been identified as a possible cause of LBP [6].

This slummed position leads to spasm of paraspinous musculature and increased pressure sensitivity of buttocks [14]. In addition, because of the necessity to keep all extremities working, the helicopter pilots have no opportunity to change position during flight $[19,26]$. Every position that results in a static muscle working leads to muscle fatigue [27]. When a muscle is under a prolonged static working the consequences are decreasing of the blood supply, decreasing of oxygen offer, production of lactic acid, muscle fatigue and pain [28]. The column also needs movement in order to keep the disc nutrition [29].

In prolonged incorrect sitting postures, the muscles, joint capsules and ligaments of the lumbar spine become fatigued. Consequently, other structures must support the joints, these tissues become quickly overloaded, fatigued, insulted and break down [6]. There are many potential factors that may lead to back pain in helicopter aircrew. The two factors most widely implicated in the etiology in helicopter crewmembers are vibration and asymmetrical/poor posture. Despite of the role of vibration in the production of symptoms remain unclear and the data implicating posture in the etiology of the Helicopter pilot LBP are more convincing $[14,15,19,30]$. Possible other factors include prolonged sitting position, lack of opportunity for shifting posture, lack lumbar support in helicopter seats, deficient ergonomics of the crew station, flight duration, and the multiplicity of variables that fall under the general category lifestyle $[10,14,16]$.

Although the association of helicopter and back pain is clearly described in the literature, only a few has been done toward to reduce this problem focused on preventing, treating, and rehabilitating back pain/injuries among active helicopter pilots. Most are recommendation, but just small number of researches is addressed to test such recommendations. The most common proposition is for redesigning seating arrangements, as well as the controls configurations in the helicopter cockpit, following the ergonomics guidelines [10,14,19,22,31]. This is followed by seat cushion vibration bearing improvement and the use of lumbar support. Only a few have advocated for back strengthening, exercise, and stretching or other related physio-regimens to address the problem. However, these ergonomic interventions are timing consuming and not financially practical, mainly in a short term. Furthermore, there is no consensus among authors on the efficacy of the suggested ergonomic modifications [6,9]. The aim of this study was to understand the pathomechanical model of the low back pain (LBP) that affects helicopter pilots in order to propose a comprehensive risk assessment to reduce this back disorder.

\section{Literature Review}

Various authors have been reported that the back pain in helicopter pilots appears after a certain amount of time spent in the air. This time depends on the pilot, the 


\section{Ergonomics International Journal}

helicopter, the type and the duration of the mission and the total flight hours $[1,30]$.

The whole stability of the spinal column occur due to the quality and the position of the vertebras, the intrinsic stiffness of its ligaments, and the muscle capacity to modulate its tension, which is capital for people who working in seated position. In addition, Studies have showed that the back deep muscles are needed for spine stabilization and have been presented an important role on the etiology, characteristics, and in the treatment of low back dysfunctions [29].

Among some important functions developed by muscles in stabilization role, can be highlighted the muscle erector spinae (ES) as responsible for the major extension force during lifting actions; the oblique abdominals producing primary the movement of rotation; The mutifidus being requested to stabilize the lower back during lifting and rotating movements. Despite of few studies regarding the low back stability and frontal plane movements, the quadratus lumborum has been pointed as a stabilizer in such movements. The abdominals have also be pointed as important stabilizers, mainly the obliques and the transversus, since its more horizontal fibers orientation contribute to the spine stabilization [29].

The muscle neural control has an important role in the vertebral stabilization, due to promote the muscle tension anticipation when any load is applied on extremities movement. The transversus and multifidus have consistent activity in preceding limbs movement in subjects without back pain history, confirming that the major contribution in keeping lower back stability is provided by back deep muscles [29]. Thus, specifics exercises addressed to training the neuron control of multifidus, the abdominals obliques and transversus, appear to be important to improve the subtle muscles recruitment pattern, which is needed for an optimum segmental stability of the lower back [29]. In addition, it has been found multifidus' weakness and local inhibition (segmental level) in the first episode of all patients with acute and sub-acute LBP [29].

Ideal posture involves an alignment of the extremities with the spine where minimal mechanical stress is applied to the supportive soft tissue (muscle, ligament, capsule, etc.) and joint bony structures. Incorrect alignment (poor posture) will produce additional mechanical demands in the supportive soft tissue and joints [6]. In addition, as the literature supports, the poor posture leads the paraspinous muscle to the fatigue [30], consequently occur a reduction in accuracy control and speed of contraction, decreasing the muscles' capacity to distributing loads [29]. Therefore, the passive structures (surrounding ligaments and tendons) will be overload to trying to keep the spine stability. During prolonged sitting in vehicles occur a posterior tilt of the pelvis, these position do not give the lumbar spine adequate support to maintain lumbar lordosis and consequently produce abnormal and excessive forces that converge in the lumbopelvic region. The nociceptive system of this region is activated by the chemically and mechanically induced stimulation resulting in pain [6].

Almost biological materials exhibits viscoelasticity behavior, which characterize that when subjected to loading and unloading presents gradual deformation and recovery. A continuous applied force beyond the elastic limit will suffer a continuous deformation [32]. Specifically in helicopter pilots, the asymmetrical posture will cause a stress-strain relationship that along the time will provoke some changes in the tissues structures as elongating some and shortening others. We can infer that the continuous effort in flying helicopter demonstrate the viscoelasticity behavior of both muscle and ligament, with change in the internal structure as an effect of the stressrelaxation and creep responses [32].

Confirming this reasoning and according to Shanahan's kinesiopathological approach [14], a kyphotic posture of the thoracic and lumbar spinal segments will result in the erector spinae and multifidus becoming weak (long). As well, the hip musculature, hamstrings and calf have the potential to lose flexibility. The loss of flexibility of the musculature of the lower extremities restricts lumbar flexion and restricts the pelvis from rotating. Restricted pelvic rotation due to loss of flexibility in the hamstrings could cause excessive mechanical stress on the low back resulting in pain. Along with weak back extensors, spinal dysfunction can develop [14,32]. The compressive load on an intervertebral disc in the kyphotic posture of the pilot is $180 \%$ of the load in the standing position [4].

Particularly in this occupational group, the muscles and ligaments in a situation of a prolonged faulty postural alignment, the static forces acting on the supportive soft tissues will alter the elasticity of these tissues. The net result may be a loss of flexibility. Repeated episodes of sustained faulty postural and contraction series, as flying helicopter, may lead to adaptive shortening of soft tissue and altering of movement performance [6]. According Pelham, et al. [6], in a helicopter pilot seated position, the spine assume a kyphotic posture, which to demand high active isometric work by the spinal extensors (primarily erector spinae and multifidus). Furthermore, the trunk flexion produces a great stress in the posterolateral area 


\section{Ergonomics International Journal}

of the annulus fibrosus, mainly with additional twisting motion and torsional loads [32].

The use of the helmet as well as the use of the night vision goggles (during night flight) forces the pilot into greater cervical extension. This position must be maintained throughout the flight $[6,33]$. In a study carried out with 21 Brazilian Air Force helicopter pilots [33] (15 with LBP - WP and 6 with no pain - NP) had found postural deviations as forward head $(100 \%$ of the pilots, WP and NP), forward shoulders (87\% among WP), posterior tilting of the pelvis and lumbar lordosis flatten (81\% among WP), indicating some change in the arrangement of the tissue structure. The author suggested that every postural deviation was caused by elongating and shortening of some muscles involved in a given joint [33]. A habitual forward head posture is usually associated with forward shoulders. Thus, it is opportune to comment about the cervical alignment once given the multi-segmental mechanical relationship of the spine, maintaining a certain degree of forward head and/or shoulder posture can be a prerequisite (precursor) for lumbar dysfunctions [6].

Another factor that probably contributes with changes in posture as well as in muscles length is the lower limb position. In order to use the pedals, the musculature of the hips, legs and ankles are constantly active, but in a shortened position. Thus, in the case of prolonged sitting of the pilot during flight, the persistent shortened state of the musculature of the hips (hip flexors), knees (hamstrings) and ankles (calf) can alter the composition and geometry of the connective tissue of the muscle $[6,19,31]$.

As a cyclic process, the shortening of the hamstring pulls down the pelvis, provoking a posterior tilting of the pelvis and consequently flattens the lumbar lordosis, which increases the stresses on the disc [33]. In a studied carried out with 171 helicopter pilots, was found a $67 \%$ LBP prevalence. Such population was characterized by its high physical activity and physical conditioning. These results suggest that the general physical conditioning as well as an active life did not appear as a factor of LBP prevention. On the other hand, when undergoing a specific program addressed to improve strength and endurance of the deep trunk muscles, the LBP severity was significantly reduced in $36 \%(p<0.001)$ [26]. In another study was de demonstrated that core strengthening exercises were effective in reducing inflight pain and led to a reduction in symptoms and disability in helicopter aircrew members [5].

\section{Methods}

\section{Literature Review Study}

It is been sought to use a literature review in order to identify evidences about low back pain in helicopter pilots, risk factors related and some interventions/risk management adopted from relevant sources. An extensive search of OVID/MEDLINE (1948 to present), Defense Technical Information Center (1945 to present) and Google Scholars (Brazil), was undertaken, using the following inclusion terms: helicopter, helicopter pilot, rotary wing, aircrew, military personnel, airspace medicine, prevalence, exercise, treatment, pilot seat, cockpit, flight deck, aviation, cockpit quality, once they were related to low back pain, back pain, back discomfort. Reference lists of retrieved articles were also searched for additional articles. Three books were also used as a source of research.

\section{Questionnaire Study}

A questionnaire was submitted to 114 Brazilian Air Force helicopter pilots. The control group comprised 351 non-flying (office workers) Air Force personnel. The questionnaire used in this study was the same used by Bongers, et al. [15]. The data collected in the mentioned questionnaire were: age, weight, height, total flight hours, average hours flown per year, type of aircraft flown, level of physical activity, characteristic, intensity and region of pain, as well as a Visual Analog Scale for pain. Questions were asked in order to establish the prevalence of back pain directly associated with flight as well as to categorize back pain as transient or chronic. For data collection in the Control Group (composed of military personnel with administrative function-office workers), an adaptation was made in the text of questions, substituting the term "flight" for "sitting position". The response rate was 73\% for both Groups. Incomplete questionnaires or filled by women were excluded, thus the whole sample consisted of 465 subjects, all males, aged between 19 and 57 years, with similar age distributions in both Groups. The questionnaire was available for download at Brazilian Air Force intranet. All commanding officers of the helicopter squadrons received, via e-mail, a cover letter explaining the research objectives, the importance of the results for pilots' health, and motivating participation. Similarly, the chief of the administrative organizations also received the same information, via e-mail. The questionnaires were anonymous in order to preserve subjects' privacy, guaranteeing strict anonymity as well as motivating participation, since most pilots are concerned about being removed from the flight activities. 


\section{Ergonomics International Journal}

\section{Statistical Analysis}

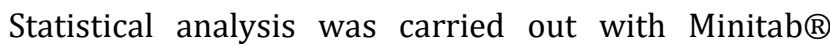
(version12, Minitab Inc., State College, PA) and SPSS $\mathbb{}$ (Released 2010. IBM SPSS Statistics Standard Grad Pack Shinkwrap, version19.0 for Windows. Armonk, NY: IBM Corp.) Software. The Chi-squared test was used for comparative analysis between the frequency distributions, derived from the crossings between the questions raised, which will form the basis of the comparative process of the calculated mean values and frequency distributions, respectively, according to the discretionary variable considered to compare. A P-value $<0.05$ was considered statistically significant.

\section{Results}

\section{Literature Review Study}

After the selected articles analysis it was found the main potential flight-related risk factors associated to the low back pain onset in helicopter pilots, as following:

- Asymmetrical in-flight posture

- Cockpit design/geometry

- Seat design

- WBV

- Static posture

- Prolonged sitting

- Flight duration

\section{Questionnaire Study}

Table 1 demonstrates that Control and Experimental Groups are quite homogeneous $(p<0.05)$ in relation to weight and height, but the Control Group presented a slightly higher age, consequently, higher exposure time and higher pain score (pain intensity).

\begin{tabular}{|c|c|c|}
\hline Variables & $\begin{array}{c}\text { Experimental Group } \\
(\mathbf{n = 1 1 4})\end{array}$ & $\begin{array}{c}\text { Control Group } \\
(\mathbf{n = 3 5 1 )}\end{array}$ \\
\hline Age (years) & $29.3 \pm 5.6$ & $35.8 \pm 9.2$ \\
\hline Weight $(\mathrm{Kg})$ & $77.7 \pm 10.1$ & $75.8 \pm 11.7$ \\
\hline Height $(\mathrm{cm})$ & $176 \pm 6$ & $174 \pm 7$ \\
\hline $\begin{array}{c}\text { Working time } \\
\text { (years) }\end{array}$ & $5.33 \pm 4.9$ & $10.95 \pm 7.6$ \\
\hline Total flight hours & $1190.2 \pm 1010.7$ & ------- \\
\hline Pain Score & $3.8 \pm 2.1$ & $5.1 \pm 2.6$ \\
\hline
\end{tabular}

Table 1: Subject Characteristics.

More than $70 \%$ of the researched helicopter pilots practiced some type of physical activity. On the other hand, the percentage of exercise practioners from the office workers was below 55\%, demonstrating a somewhat sedentary lifestyle when compared to the pilots (Figure 1).

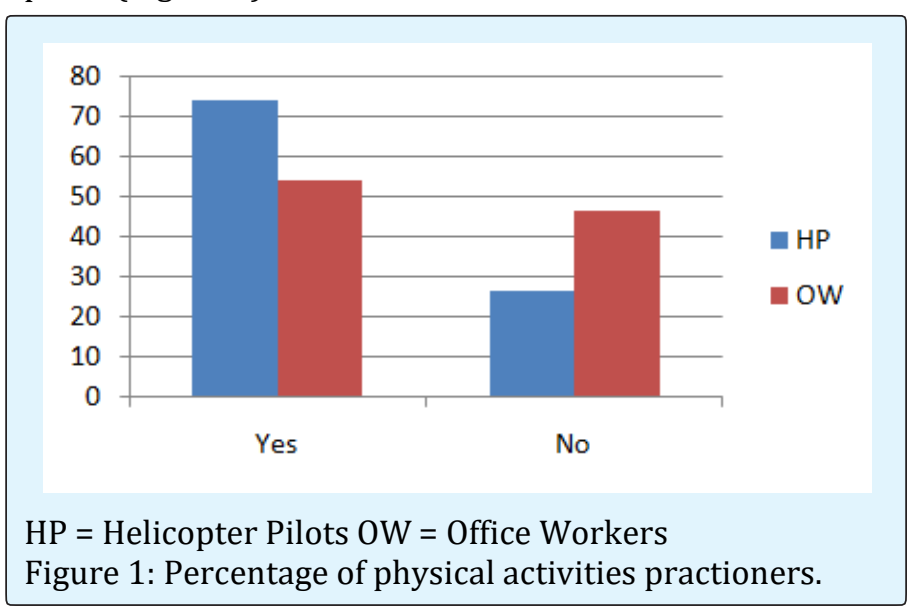

When asked about backache, the HP prevalence was $66.7 \%$ and the OW prevalence was $49 \%$. The LBP prevalence was $60.5 \%$ in HP and $36.5 \%$ among the office workers (Figure 2).

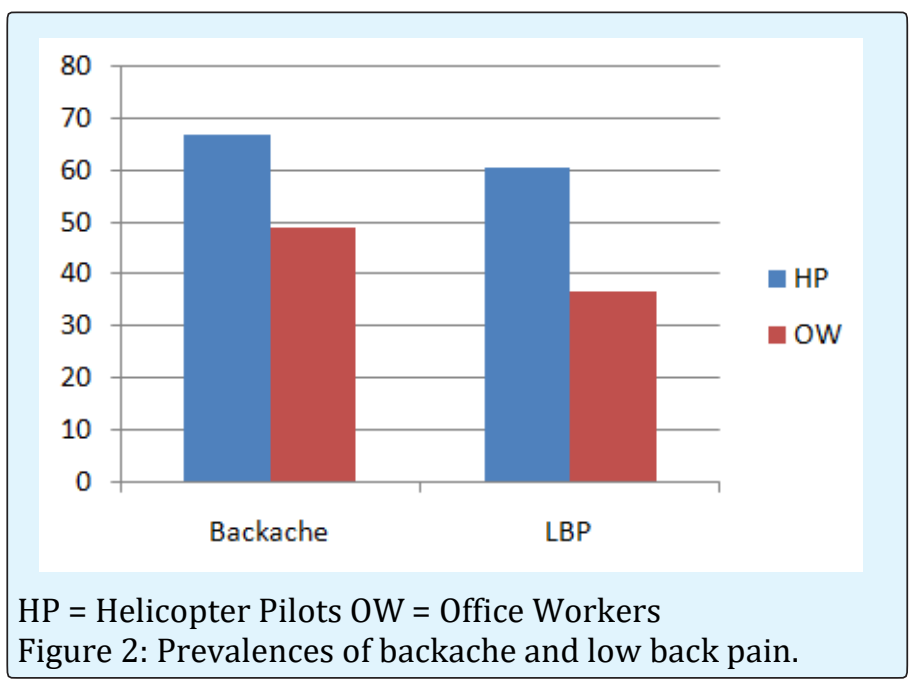

As can be seen at Figure 3, the frequency, persistence, pattern, as well as non-radiation to the legs or lack of medical treatment, characterized the pain reported by the helicopter pilots as transient. Conversely, in general, pain presented by the Control Group presents characteristics of chronicity. More than $30 \%$ of the pilots reported pain during or immediately after the flight and only $16 \%$ stated that the pain was not associated with flight activity, which means that $84 \%$ associate LBP to flight. Among the pilots who reported LBP, the most common situation (above 45\%) was during or immediately after a flight lasting more than two hours. Only $11 \%$ of the $0 \mathrm{~W}$ did not associate the pain to work. 


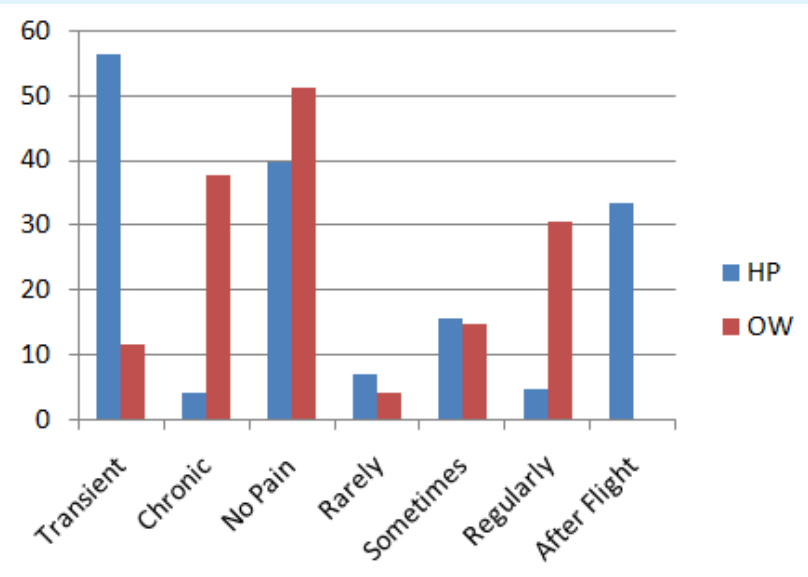

HP = Helicopter Pilots OW = Office Workers

Figure 3: LBP characteristics and frequency.

\section{Discussion}

The homogeneity of the sample, in terms of weight and height, as well as the age range, which also correspond to productive age, are very positive factors of the study, allowing a better comparison with other studies about this subject. The results showed a significant difference ( $p$ $<0.05$ ) in the initial levels of pain intensity (pain score), with the Control Group showing higher pain severity when compared to the Experimental Group. It can also be observed that even pilots been considered as physically active, the prevalence of LBP was higher $(60.5 \%)$ when compared to OW (35.6\%). Such verification suggests that the practice of physical activity by itself is not a determining factor in the prevention of LBP in pilots.

This finding is not supported by Mohler [37], who advocate physical conditioning as a preventive factor for LBP, and corroborates with studies by O'Sullivan, et al. [36] and Da Silva, et al. [26], suggesting that physical conditioning is not the most important factor in the prevention of LBG, but the use of specific exercises for the muscles of the trunk aiming at the improvement of strength, endurance, flexibility and spine stabilization $[5,6,8,26,33-36]$. Taking into account only the pilots with complaints of back pain, this average recurrent/transient pain rate corresponds to $93 \%$. These findings confirm the rates raised several authors [4,13,14,16,21], reinforcing the theory that most pilots suffer from low back pain during or immediately after the flight, ceasing after a brief rest period, suggesting muscle fatigue, mainly due to poor in-flight posture $[5,6,8,21,26,30]$. In addition, among the situations indicated by the pilots, in whom they felt the presence of LBP, it was the most common one that occurred during or immediately after flights lasting more than two hours, confirming the results verified by Froom, Da Silva and Balasubramanian, et al. $[4,26,30]$, also reinforcing the pilots' awkward sitting posture in helicopters as a major factor [21].

The Chi-square results demonstrated that flight activity has great influence not only on the prevalence $(p=0.00008)$, but also on the characteristics of pain (pattern, frequency, persistence, intensity), spinal region on pain manifests, type of pain (chronic and transient), confirming the recurrent pain characteristic that affects pilots $(p<0.0000001)$. The characterization of HP low back pain as a transient one, demonstrated that the LBP presented by this population has its own characteristics and that this characteristic suggests the muscular fatigue as one of the etiological factors $[5,6,16,21,26,30,34,35]$. In spite of most paper do not taken into account the risk management; it can be deducted from some comments and results, which can support the adoption of some actions as limiting the flight duration in 2 hours, when it is possible, and the using of pilot-fitting lumbar support $[2,3,9,10,38]$. A pre- and post-flight exercise protocol, based on proprioceptive Neuromuscular Facilitation (PNF) stretching that has been practiced by selected Canadian Forces (CF) Base Shearwater helicopter aircrew was proposed. Although do not presenting any data about the results, the authors affirm that this flight specific training is an essential factor assisting aviators to achieve and maintain the high levels of function required by $\mathrm{CF}$ personnel [6].

More recently, a study testes a set of five core strengthening exercises performed 4 days per week for 12 weeks in 12 US Air Force Helicopter Crewmembers with Low Back Pain, concluding that core exercises applied to this small number of subject were effective in reducing in-flight pain and led to a reduction in pain symptoms and disability as compared to those subjects who maintained their regular exercise regimen [5].

\section{Risk Factors and Pathomechanical Model}

Based on the evidence gathered from both literature review and questionnaire study it can be inferred that pathomechanics of helicopter pilots LBP is a combination of four factors, when the (1) asymmetric posture (bending forward, twisting and bending to the left) is the main cause, once it requests a great effort of the back muscles producing fatigue, and fatigue often leads to pain. In addition, the pilots remain (2) static in this position for a prolonged time, which contributes to local tissue ischemia accelerating the muscle fatigue process. Another factor is the (3) prolonged seated position, which is by itself an overloading to the lower back whereas, flattens the lumbar lordosis increasing the intervertebral disc 


\section{Ergonomics International Journal}

pressure. Finalizing the whole process there is the (4) whole body vibration acting potentially due to increase

the power of the other previous three factors (Figure 4).

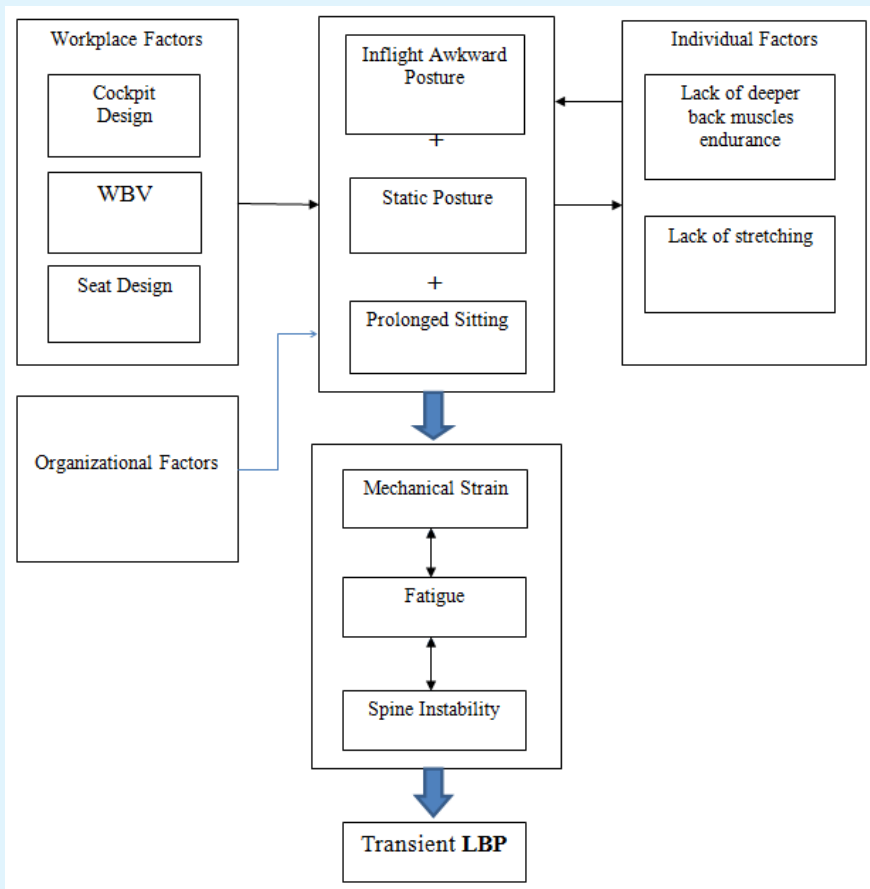

Figure 4: A pathomechanical model of low back pain in helicopter pilots.

\section{Risk Management}

According to all aspects described and detailed previously during the literature review and questionnaire study, both summarized in theoretical model (Figure 1), the solution for the problem will be formed by three different and complementary steps: exercise program, use of personal lumbar support, and proposal for redesign cockpit and seat.

Therefore, due to the expected high costs of some of the solutions to be implemented as well as the necessity to be approved by high level of decision, as commented on Table 2; the risk management will be implemented in three distinct moments: as a first step, an immediate solution based on a specific exercise program (to be better explainer further in this paper), followed by a short term solution, which will provide a pilot-fitting lumbar support, and as a long term solution, the ergonomic improvements in the cockpit and seat design (proposal). Also as part of the immediate solution, the organizational/operational actions can be implemented in order to manage the effects of flight duration (e.g. planning flights no longer than 2 hours, when it is possible; including the in-flight self-stretching exercises as an operational procedure). The Table 2 shows the descriptions of the proposed solutions.

\begin{tabular}{|c|c|}
\hline Solutions & Description of the actions/improvements \\
\hline Redesigning of the Cockpit & $\begin{array}{c}\text { - Bring the cyclic and the collective closer to the pilots body; } \\
\text { - Developing a forearm support to the right arm (using the collective) }\end{array}$ \\
\hline Improvement of the Seat Design & $\begin{array}{c}\text { - Improvements in back design (more contours) with a good lumbar support } \\
\text { - Improvements in thigh support (design and cushion to absorb vibration) } \\
\text { Improvements in the adjustment range in all axes, including arm rest and pedals }\end{array}$ \\
\hline Personal Lumbar Support & $\begin{array}{c}\text { Making personal pilot-fitting lumbar support } \\
\text { • Provide it to all helicopter pilots }\end{array}$ \\
\hline Specific Exercises Program & $\begin{array}{c}\text { - The program have to combine strength, stabilizing and flexibility exercises; } \\
\text { The strength, stabilizing and flexibility exercises must be under supervision and } \\
\text { orientation; }\end{array}$ \\
\hline
\end{tabular}




\section{Ergonomics International Journal}

\begin{tabular}{|c|c|}
\hline & $\begin{array}{c}\bullet \text { Must be complemented by self-stretching exercises (pre-, in-, and post-flight, and a } \\
\text { pre- and post-sleeping). }\end{array}$ \\
\hline Management in flight duration & $\begin{array}{c}\bullet \text { Planning flights no longer than 2 hours (when it is possible); } \\
\bullet \text { Including the in-flight self-stretching exercises as an operational procedure. }\end{array}$ \\
\hline
\end{tabular}

Table 2: The description of the proposed possible solutions

In order to better clarify the differences among the proposed solutions and its implementation, the Table 3 was created to show the advantages and disadvantage of each solution previous commented.

\begin{tabular}{|c|c|c|}
\hline Solutions & Advantages & Disadvantages \\
\hline Redesigning of the Cockpit & $\begin{array}{c}\bullet \text { Improvement of the pilot in-flight position } \\
\bullet \text { Permanent }\end{array}$ & $\begin{array}{c}\bullet \text { Long term implementation; } \\
\bullet \text { High Cost }\end{array}$ \\
\hline $\begin{array}{c}\text { Improvement of the Seat } \\
\text { Design }\end{array}$ & $\begin{array}{c}\bullet \text { Improvement of the pilot in-flight position } \\
\bullet \text { Permanent }\end{array}$ & $\begin{array}{c}\bullet \text { Medium term implementation } \\
\bullet \text { Considerable cost }\end{array}$ \\
\hline $\begin{array}{c}\text { Personal Lumbar Support } \\
\text { Specific Exercises Program }\end{array}$ & $\begin{array}{c}\bullet \text { Improvement of the pilot in-flight position } \\
\bullet \text { Low cost }\end{array}$ & $\begin{array}{c}\bullet \text { Despite de amount, but have cost } \\
\bullet \text { Palliative solution } \\
\bullet \text { Lack of strong evidence }\end{array}$ \\
\hline & $\begin{array}{c}\bullet \text { Short term implementation } \\
\text { - Improvement of the overall health; } \\
\bullet \text { Permanent }\end{array}$ & $\bullet$ Needs to be carrying out frequently. \\
\hline
\end{tabular}

Table 3: Comparison among proposed possible solutions

Regarding the factors described on the Pathomecanical Model (Table 4), as well as the comparison among the possible solutions (Table 3), a specific program for helicopter aircrew considering the muscles involved with the flight has been developed, as an immediate solution. Therefore, the Table 4 was set in order to better explain how the proposed specific exercise program will work and the reasoning used to develop it.

\begin{tabular}{|c|c|c|c|}
\hline Etiologic Factors & Mechanism & Proposed Treatment & Expected Effect \\
\hline Asymmetrical Posture & $\begin{array}{c}\text { The trunk position in-flight } \\
\text { (bend forward, twist to the left } \\
\text { and bend to the left) is a great } \\
\text { effort to the paraspinous } \\
\text { muscles, leading to a fatigue }\end{array}$ & $\begin{array}{l}\text { Specifics exercises (stabilization } \\
\text { and endurance) considering the } \\
\text { muscles involved in the flight } \\
\text { activity } \\
\text { - Pre- and Post-flight stretching }\end{array}$ & $\begin{array}{l}\text { Increase the muscle strength } \\
\text { and endurance } \\
\text { - Produce a general muscle } \\
\text { palance, improving the genera } \\
\text { posture }\end{array}$ \\
\hline Static Position & $\begin{array}{c}\text { This position leads to a great } \\
\text { sometric contraction that leads } \\
\text { decrease in the blood supply, } \\
\text { oxygen delivery, and deficient } \\
\text { disc nutrition, producing fatigue } \\
\text { and pain. }\end{array}$ & $\begin{array}{l}\text { - Stretching exercises } \\
\text { - Pre-, During and Post flight } \\
\text { - Pre- and Post-sleeping }\end{array}$ & $\begin{array}{l}\text { - Increase the length of the } \\
\text { muscles } \\
\text { - Improve blood supply } \\
\text { process } \\
\text { - Prevent fatigue } \\
\text { - Improve disc nutrition }\end{array}$ \\
\hline
\end{tabular}




\section{Ergonomics International Journal}

\begin{tabular}{|c|c|c|c|}
\hline $\begin{array}{c}\text { Prolonged Sitting } \\
\text { Position }\end{array}$ & $\begin{array}{c}\text { Shortens the lower limbs } \\
\text { muscles, contributing to flat } \\
\text { more the lumbar lordosis. }\end{array}$ & $\begin{array}{c}\text { - Stabilizing exercises } \\
\text { Oriented flexibility exercises } \\
\text { (FNP) } \\
\text { Vuring flight stretching. }\end{array}$ & $\begin{array}{c}\text { Improve the co-contraction } \\
\text { capacity } \\
\text { Improve posture, elongating } \\
\text { the shortened, and strengthen } \\
\text { the weakened muscles } \\
\text { - Improve disc nutrition. }\end{array}$ \\
\hline Vibration & $\begin{array}{c}\text { It working in order to worsened } \\
\text { the other three factors. }\end{array}$ & $\begin{array}{c}\text { Improve the pilot specific } \\
\text { physical conditioning, } \\
\text { strength, endurance, } \\
\text { flexibility, and the spinal } \\
\text { stabilizer ability. }\end{array}$ \\
\hline
\end{tabular}

Table 4: How does the proposed specific exercise program will work?

Regarding the biomechanical issues and the supposed muscles and ligaments adaptation due to the flying effort and/or in-flight posture lead them to shorten and elongation, a physical program matching exercises that acts against these undesirables muscle adaptations, might be an effective treatment and a preventive action. Furthermore, besides to be an inexpensive solution, a specific program considering the flight effort will acting in both main factors, does not matter if the onset was posture or vibration.

Within this approach due to provide a comprehensive program to prepare pilots for their operational duties and to prevent back pain and matching the demands of the helicopter flight our proposal is a program that combine strength, stabilizing and flexibility exercises in order to minimize the most of mechanical factors.

The Program is composed of two parts, one with strength, stabilizing and flexibility exercises under supervision and orientation and other part composed only by flexibility exercises and without supervision. This second part, made of stretching exercises is still subdivided into two others, a pre-, during, and post-flight, and a pre- and post-sleeping.

\section{Conclusion}

The transient characteristic of LBP in PH, as well as its strong association with flight, occurring mainly during or immediately after flight, allows inferring that this pain can have its origin of muscular nature, in principle, as a result of an inadequate and static posture over a long period of time, also receiving a synergistic action from vibration.

Although it is very difficult to define the etiology of this back disorder, it can be considered that the asymmetrical posture that the pilot is forced to assume during the helicopter flight (forward-bent, left twisted and left tilted position) imposes a great effort on the vertebral musculature, mainly on the deep muscles involved in the maintenance of this awkward posture and in the stabilization of the spine. This inadequate and exhausting posture, maintained for long periods without the opportunity to make modifications of position, leads to muscles fatigue and pain. Added to this situation and acting synergistically, vibration is an aggravating factor, since it provides great physical demanding, which contribute to the onset of muscle fatigue.

The great concern of prove the main etiologic factor of the LBP that affects helicopter pilots, maybe has avoided studies to be addressed to find new approaches, and concern about practical and effective solutions to reduce the problem, or even a palliative treatment. In addition, the most logic solution which is to ergonomically redesign the seat and the cockpit takes a long time to be implemented as well as high costs, and high level of decisions. Therefore, the best solution has been blinded the researchers to seek intermediary, simpler, and low costs solutions. In other words, the action would be addressed to the individual factors.

The results of the literature review showed that only a few studies were addressed to test specific helicopter aircrew treatment and/or solution, most of them presenting only suggestions, corroborating the statement that have been studied a lot about helicopter and low back pain, but little few has been done to reduce this problem. In order to solve the problem it will be necessary to provide a comprehensive solution (risk management) composed by three different and complementary steps: a specific exercise program (as an immediate solution), the use of personal lumbar support (as a short term solution), and a proposal for redesign cockpit and seat (as a long term solution). In a short term, most studies should be addressed to practical application on pilots' health and interventions in mitigating LBP 
severity and morbidity. For near future, further studies should to be carrying out regarding the specific solution/modification in the seat and cockpit design, following the ergonomic guidelines.

\section{References}

1. Bowden T (1987) Back pain in helicopter aircrew: A literature review. Aviation Space Environmental Medicine 58(5): 461-467.

2. Hansen OB, Wagstaff AS (2001) Low back pain in Norwegian helicopter aircrew. Aviation Space Environmental Medicine 72(3): 161-164.

3. Cunningham LK, Docherty S, Tyler AW (2010) Prevalence of low back pain (LBP) in rotary wings aviation. Aviation Space Environmental Medicine 81(8): 774-778.

4. Froom P, Barzilay J, Caine Y, Margaliot S, Forecast D, et al. (1986) Low back pain in pilots. Aviat Space Environ Med 57(7): 694-695.

5. Brandt Y, Currier L, Plante TW, Kabban CMS, Tvaryanas AP (2015) A Randomized Controlled Trial of Core Strengthening Exercises in Helicopter Crewmembers with Low Back Pain. Aerosp Med Hum Perform 86(10): 889-894.

6. Pelham TW, White H, Holt LE, Lee SW (2005) The etiology of low back pain in military helicopter aviators: Prevention and treatment. Work 24(2): 101110.

7. Grossman A, Nakdimon I, Chapnik L, Levy Y (2012) Back Symptoms in Aviators Flying Different Aircraft. Aviat Space Environ Med 83(7): 702-705.

8. Da Silva GV (2006) The effect of the low back pain over the pilots' operational duties and flight safety in the Brazilian Air Force. Air Force University Magazine 22: 5-12.

9. Thomae MK, Porteous JE, Brock JR, Allen GD, Heller RF (1998) Back pain in Australian military helicopter pilots: A preliminary study. Aviat Space Environ Med 69(5): 468-473.

10. Sheard SC, Pethybridge RJ, Wright JM, McMillan GH (1996) Back pain in aircrew: an initial survey. Aviat Space Environ Med 67(5): 474-477.

11. Bridger RS, Groom MR, Jones H, Pethybridge RJ, Pullinger N (2002) Task and postural factors are related to back pain in helicopter pilots. Aviat Space Environ Med 73(8): 805-811.

12. Winfield DA (1999) Aircrew lumbar supports: An update. Aviat Space Environ Med 70(4): 321-324.

13. Da Silva GV (2002) Prevalence of low back pain in military and civilian helicopter pilos. 9th Congress of Physical Education and Sports Science of the Portuguese Language Countries.

14. Shanahan DF, Reading TE (1984) Helicopter pilot back pain: A preliminary study. Aviat Space Environ Med 55(2): 117-121.

15. Bongers PM, Hulshof CT, Dijkstra L, Boshuizen HC, Groenhout HJ, et al. (1990) Back pain and exposure to whole body vibration in helicopter pilots. Ergonomics 33(8): 1007-1026.

16. Gaydos SJ (2012) Low Back Pain: Considerations for Rotary-Wing Aircrew. Aviat Space Environ Med 83(9): 879-889.

17. Shanahan DF, Mastroianni GR, Reading TE (1986) Back discomfort in US Army helicopter flight crew members. AGARD Conference Proceedings $\mathrm{N}^{\circ}$ 378: Backache and Back Discomfort 6: 6-10.

18. Thornton R, Vyrnwy-Jones P (1984) Environmental factors in helicopter operations. J R Army Med Corps 130(3): 157-161.

19. Lopez-Lopez JA, Vallejo P, Rios-Tejada F, Jimenez R, Sierra I, et al. (2001) Determination of lumbar muscular activity in helicopter pilots: A new approach. Aviat Space Environ Med 72(1): 38-43.

20. Froom P, Hanegbi R, Ribak J (1987) Low back pain in the AH-1 Cobra Helicopter. Aviat Space Environ Med 58(4): 315-318.

21. Kåsin JI, Mansfield N, Wagstaff A (2011) Whole Body Vibration in Helicopters: Risk Assessment in Relation to Low Back Pain. Aviat Space Environ Med 82(8): 790-796.

22. Orsello CA, Phillips AS, Rice GM (2013) Height and InFlight Low Back Pain Association among Military Helicopter Pilots. Aviat Space Environ Med 84(1): 3237.

23. Oliveira CG, Nadal J (2004) Back muscle EMG of helicopter pilots in flight: effects of fatigue, vibration, and posture. Aviat Space Environ Med 75(4): 317-22. 
24. Oliveira CG, Nadal J (2005) Transmissibility of helicopter vibration in the spines of pilots in flight. Aviation, Space and Environmental Medicine 76(6): 576-580.

25. Oliveira CG, Simpson D, Nadal J (2001) Lumbar Back Muscle Activity of Helicopter Pilot and Whole-Body Vibration. J Biomech 34(10): 1309-1315.

26. Da Silva GV (2004) Proposal of a specific exercise program and low back relief in helicopter pilots. Thesis, pp: 1-276.

27. Oliver J, Middleditch A (1998) Anatomia Funcional da Coluna Vertebral $1^{\text {st }}$ (Edn.), Revinter, Rio de Janeiro.

28. Gradjean E (1998) Manual De Ergonomia-Adaptando o Trabalho Ao Homem $4^{\text {th }}$ (Edn.), Porto Alegre, Brazil.

29. Panjabi M, Abumi K, Duranceau J, Oxland T (1989) Spinal stability and intersegmental muscle forces-a biomechanical model. Spine 14(2): 194-200.

30. Balasubramanian V, Dutt A, Rai S (2011) Analysis of muscle fatigue in helicopter pilots. Appl Ergon 42(6): 913-918.

31. Grant KA (2002) Ergonomic assessment of a helicopter crew seat: The HH-60G flight engineer position. Aviat Space Environ Med 73(9): 913-918.

32. Nordin M, Fransen T (2001) Basic Biomechanics of the Musculoskeletal System $3^{\text {rd }}$ (Edn.), Lippincott Willians \& Wilkins, Baltimore, USA.
33. Da Silva GV, Silva MAG, Rodriguez CG, Bomfim ABC (2005) Muscle dysfunction and low back pain in helicopter pilots. Fisiot Brasil 6: 18-26.

34. Beach A (1985) A review of the pilot backache problem in the $\mathrm{CH} 113$ Labrador helicopter. Defence and Civil Institute of Environmental Medicine, Toronto, Canada, Report No: DCIEM-85-R-49.

35. Ladner TJ (1997) Back pain and endurance training of back muscles: justification for further study in helicopter pilots. TX: Air Force Institute of Technology, Houston School of Public Health, Houston, Report No: 97-047.

36. O'Sullivan PB, Phyty GD, Twomey LT, Allison GT (1997) Evaluation of specific stabilizing exercise in treatment of chronic low back pain with radiologic diagnosis of spondylolysis and spondylolisthesis. Spine 22(24): 2959-2967.

37. Mohler SR (2000) Lower back pain is a common complaint, but precautionary practices help pilots cope. Human factors \& aviation medicine 47(3): 1-6.

38. Aota $Y$, Iizuka H, IshigeY, MochidaT, Yoshihisa, T, et al. (2007) Effectiveness of a lumbar support continuous passive motion device in the prevention of low back pain during prolonged sitting. Spine 32(23): E674E677. 